\title{
NON-EPILEPTIC MANIFESTATIONS IN PATIENTS WITH SINGLE ENHANCING COMPUTED TOMOGRAPHY LESIONS IN A TERTIARY CARE CENTRE OF BIHAR
}

\author{
Anuj Kumar1, Jyoti Kumar Dinkar², Naresh Kumar ${ }^{3}$ \\ ${ }^{1}$ Consultant Physician, Department of General Medicine, Shivam Clinic, Bailey Road, Patna. \\ ${ }^{2}$ Senior Resident, Department of General Medicine, Indira Gandhi Institute of Medical Sciences, Patna. \\ ${ }^{3}$ Professor and HOD, Department of General Medicine, Indira Gandhi Institute of Medical Sciences, Patna.
}

\section{ABSTRACT}

\section{BACKGROUND}

Single small ring enhancing computed tomography lesion is a clinicoradiological abnormality being reported more frequently as imaging of the brain becomes more prevalent. It is a common abnormality on imaging in young patients of low socioeconomic status presented with acute symptomatic seizures in tropical and developing countries like India. Neurocysticercosis and Tuberculoma are the commonest ring forming granulomas. Apart from the seizure, many varieties of other neurological manifestations have been observed in these cases of single ring enhancing lesions found on the computed tomography scan of brain.

The objective of the present study is to identify the non-epileptic manifestations of single ring enhancing computed tomography lesions.

\section{MATERIALS AND METHODS}

This is a descriptive study conducted in Neurology Unit of Department of General Medicine, Patna Medical College and Hospital Patna, Bihar. A total of 52 patients of age group 20-60 years with acute onset non-epileptic disorder having symptoms and signs other than seizure as presenting complaint with no evidence of other associated systemic diseases were included. A detailed clinical history with thorough clinical examination along with haematological and biochemical parameters were obtained in all patients. All patients were subjected to non-contrast and contrast-enhanced computed tomography of brain at the time of initial evaluation and repeated after 8-12 weeks of duration.

\section{RESULTS}

Out of 52 patients, it was observed that prevalence of non-epileptic manifestations of single ring enhancing CT lesions were higher in younger age group with no gender predilection. Among the non-epileptic manifestations, headache with or without vomiting $(19.23 \%)$ was the most common and hemiparesis $(15.38 \%)$ either of left or right side was the second most common presentation followed by hemichorea (11.54\%) and homonymous hemianopia (11.54\%). The incidence of single ring enhancing lesion was more prevalent in patients belonging to low socioeconomic status.

\section{CONCLUSION}

Although seizure is the commonest presentation in patients with single ring enhancing lesion on computed tomography, the manifestations may vary. The heterogenous localisation of the parasite or bacteria in the brain, variable inflammatory responses in surrounding tissue and inconsistent natural history are responsible for pleomorphic manifestations of the disease.

\section{KEYWORDS}

Non-epileptic, Manifestations, Neurocysticercosis, Tuberculoma, Computed Tomography, Single Ring Enhancing Lesion.

HOW TO CITE THIS ARTICLE: Kumar A, Dinkar JK, Kumar N. Non-epileptic manifestations in patients with single enhancing computed tomography lesions in a tertiary care centre of Bihar. J. Evolution Med. Dent. Sci. 2017;6(85):5890-5892, DOI: $10.14260 /$ jemds $/ 2017 / 1280$

\section{BACKGROUND}

A single small enhancing computed tomography lesions are a common finding on imaging in young patients presented with acute symptomatic seizures in tropical and developing countries like India. ${ }^{1-4}$ These lesions typically are small (often $\leq 20 \mathrm{~mm}$ ), enhancing as a ring lesion or a disc and with varying amounts of surrounding oedema. Usually there is neither any significant midline shift nor enhancing exudates.

'Financial or Other Competing Interest': None.

Submission 28-08-2017, Peer Review 07-10-2017,

Acceptance 14-10-2017, Published 23-10-2017.

Corresponding Author:

Jyoti Kumar Dinkar,

Senior Resident,

Department of General Medicine,

Indira Gandhi Institute of Medical Sciences,

Patna-800014, Bihar.

E-mail: drdinkar03@gmail.com

DOI: $10.14260 /$ jemds $/ 2017 / 1280$

\section{(c) (i) $\odot$}

Several retrospective studies have reported that these small enhancing CT lesions resolve spontaneously. ${ }^{3,5}$ In several other studies, ${ }^{6-8}$ these CT lesions have been treated with anticysticercal drugs, however, with conflicting results. Neurocysticercosis and Tuberculoma are the commonest ring forming granulomas and they respond well with their respective treatment. Seizure is the commonest manifestation of these granulomas.

Human cysticercosis is a global health problem. It is endemic in Mexico, India, central and south America and China. Cysticercosis is a parasitic disease that results when human serves as an intermediate host of 'Taenia solium' the pork tapeworm. The heterogenous localisation of the parasite in the brain, variable inflammatory responses in surrounding tissue and inconsistent natural history are responsible for pleomorphic manifestations of the disease.

A Tuberculoma is a tumour like mass of typical tubercular granulomatous disease, which produces symptoms of space occupying lesion. They may be multiple and frequently follow 
a known episode of tuberculous meningitis. Tuberculosis of central nervous system accounts for $5 \%$ of extrapulmonary cases. The disease affects the young; $50 \%$ cases occur in children under 10 years of age and nearly $80 \%$ in those below 30 years of age. It is seldom seen above the age of 55 years.

It has been observed that many varieties of neurological manifestations other than seizure are presenting features in these cases of single ring enhancing lesions found on the CT scan. Hence, the objective of the present study is to prospectively know the non-epileptic manifestations in patients with single ring enhancing computed tomography lesions.

\section{MATERIALS AND METHODS}

The present descriptive study was carried out in Neurology Unit of Department of General Medicine, Patna Medical College and Hospital, Patna, Bihar. This study included a total of 52 patients in the age group of 20-60 years, attending medicine inpatient or outpatient clinic with acute onset nonepileptic disorder having symptoms and signs other than seizure as presenting complaint and a single ring enhancing lesion on computed tomography of brain with no evidence of other associated systemic diseases. Patients with a previous history of cerebrovascular accidents, cerebrovascular diseases, head injuries, road traffic accidents, meningitis, encephalitis and having complaint of seizure disorders were excluded from the study. Computed tomography criteria for inclusion of the patients in the present study were presence of a small ring lesion ( $\leq 20 \mathrm{~mm}$ in maximal dimension), which may enhance on contrast use, having no midline shift and with the presence or absence of associated oedema around the lesion. All patients participated in the present study were subjected to non-contrast and contrast-enhanced computed tomography of brain at the time of presentation and repeated after 8-12 weeks of initial evaluation. A detailed clinical history and neurological examination with detailed haematological and biochemical parameters consisting of complete blood count, erythrocyte sedimentation rate, blood sugar, blood urea, serum creatinine were obtained. The chest was x-rayed in each patient for pulmonary tuberculosis and primary or metastatic lesion of lung. Lumbar puncture and cerebrospinal fluid examination, ELISA for detection of anti Taenia solium and anti-mycobacterium antibodies in serum and cerebrospinal fluid were also done in all patients.

Data was documented using statistical package for social sciences (SPSS) version 16 and Microsoft excel 7.

\section{RESULTS}

Out of 52 patients participated in the study, it was observed that non-epileptic manifestations of single ring enhancing CT lesions were higher in the age group of 20-40 years (53.84\%), and there was no gender predilection [Table $1 \&$ Fig. 1]. The incidence was more or less same in both sexes. Out of 52 cases, 33 (63.46\%) belonged to low socioeconomic status. 16 $(30.76 \%)$ and $3(5.76 \%)$ cases belonged to middle and upper socioeconomic status respectively [Table 2]. In the present study, among the non-epileptic manifestations, headache with or without vomiting $(10,19.23 \%)$ was the most common presentation followed by hemiparesis $8(15.38 \%)$, either of right or left, homonymous hemianopia 6 (11.54\%), and hemichorea $6(11.54 \%)$ in cases of single ring enhancing computed tomography lesion [Table-3]. Out of total 52 cases, the most common location of lesion on CT was parenchymal $48(92.3 \%)$. The lesion was found in ventricle in only 4 (7.69\%) of cases [Table 4]. CSF picture was found to be normal in about $50 \%$ of cases. Out of total 52 cases, lumbar puncture was not done in 4 cases due to raised intracranial pressure. Neurocysticercosis and Tuberculoma were found in 18 and 22 patients respectively. Out of total 52 cases, 36 (69.23\%) patients showed complete disappearance of CT lesion after 8-12 weeks of initial treatment and followup.

\begin{tabular}{|c|c|c|}
\hline Age (In years) & No. of Cases & Percentage \\
\hline $0-20$ & 20 & 38.46 \\
\hline $20-40$ & 28 & 53.85 \\
\hline $40-60$ & 04 & 7.69 \\
\hline \multicolumn{2}{|c|}{ Table 1. Age Distribution of Cases of } \\
Single ring Enhancing CT Lesions \\
\hline
\end{tabular}

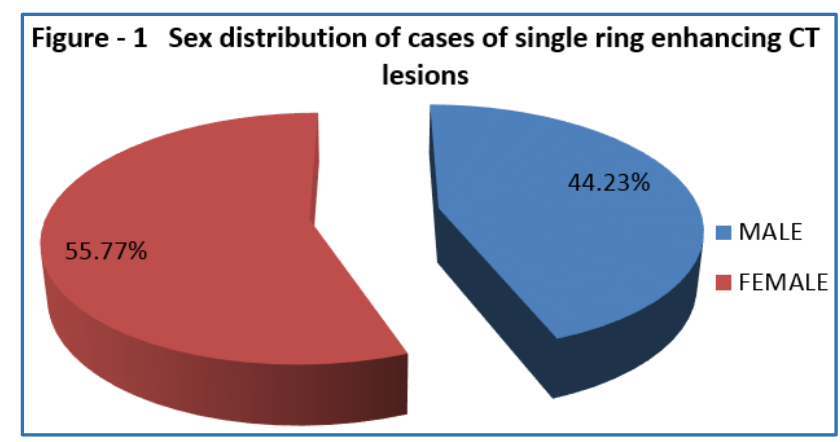

\begin{tabular}{|c|c|c|}
\hline Socioeconomic Status & No. of Cases & Percentage \\
\hline Lower & 33 & 63.46 \\
\hline Middle & 16 & 30.77 \\
\hline Upper & 3 & 5.77 \\
\hline \multicolumn{2}{|r|}{$\begin{array}{r}\text { Table 2. Socioeconomic Status of } \\
\text { Cases of Single ring Enhancing CT lesions }\end{array}$} \\
\hline
\end{tabular}

\begin{tabular}{|c|c|c|c|}
\hline $\begin{array}{l}\text { Sl. } \\
\text { No. }\end{array}$ & Manifestations & $\begin{array}{l}\text { No. of } \\
\text { cases }\end{array}$ & $\%$ \\
\hline 1 & $\begin{array}{c}\text { Episodic vascular type of } \\
\text { headache with or without vomiting }\end{array}$ & 10 & 19.23 \\
\hline 2 & $\begin{array}{l}\text { Headache due to raised intracranial } \\
\text { pressure }\end{array}$ & 4 & 7.69 \\
\hline 3 & Crural monoparesis & 4 & 7.69 \\
\hline 4 & Broca's aphasia & 3 & 5.77 \\
\hline 5 & $\begin{array}{l}\text { Broca's aphasia with } \\
\text { upper limb weakness }\end{array}$ & 2 & 3.85 \\
\hline 6 & Hemiparesis & 8 & 15.38 \\
\hline 7 & Hemiplegia & 5 & 9.61 \\
\hline 8 & Homonymous hemianopia & 6 & 11.54 \\
\hline 9 & Hemichorea & 6 & 11.54 \\
\hline 10 & Acute confusional state & 4 & 7.69 \\
\hline \multicolumn{4}{|c|}{ Table 3. Non-epileptic Manifestations in } \\
\hline
\end{tabular}

\begin{tabular}{|c|c|c|}
\hline Location of Lesion & No. of Cases & Percentage \\
\hline Parenchymal only & 48 & 92.3 \\
\hline Cistern only & 0 & 0 \\
\hline Ventricle only & 4 & 7.69 \\
\hline \multicolumn{3}{|c|}{ Table 4. CT Scan study for Location } \\
\hline
\end{tabular}




\begin{tabular}{|c|c|c|c|c|c|c|c|}
\hline $\begin{array}{c}\text { Lesion } \\
\text { Disappeared }\end{array}$ & \multicolumn{2}{c|}{$\begin{array}{c}\text { Lesion } \\
\text { Calcified }\end{array}$} & \multicolumn{2}{c|}{$\begin{array}{c}\text { Lesion } \\
\text { Regressed }\end{array}$} & $\begin{array}{c}\text { Lesion- Same } \\
\text { Size }\end{array}$ \\
\hline No. & $\%$ & No. & $\%$ & No. & $\%$ & No. & $\%$ \\
\hline 36 & 69.23 & 6 & 11.53 & 8 & 15.38 & 2 & 3.85 \\
\hline \multicolumn{6}{|c|}{ Table 5. Results of Followup CT scan after } \\
8-12 weeks following Treatment \\
\hline
\end{tabular}

\section{DISCUSSION}

The purpose of the present study entitled non-epileptic manifestations of single ring enhancing computed tomography lesion was to know the varieties of presentation of this disease other than seizure. Although simple partial seizure with or without secondary generalisation is the commonest seizure type seen in these patients irrespective of CT lesions, the presentation of patients with this disease, however, may vary. In our study, episodic vascular type of headache with or without vomiting $(19.23 \%)$ was the most common presentation, the second most common presentation was hemiparesis (15.38\%) either of right or left side, followed by hemichorea $(11.54 \%)$ and homonymous hemianopia (11.54\%). Other manifestations of patients with single ring enhancing CT lesions were hemiplegia (9.61\%), headache due to raised intracranial pressure $(7.69 \%)$, crural monoparesis (7.69\%), acute confusional state (7.69\%), Broca's aphasia (5.76\%) and Broca's aphasia with upper limb weakness $(3.85 \%)$. The heterogenous localisation of the parasite or bacteria in the brain, variable inflammatory responses in surrounding tissue and inconsistent natural history are responsible for pleomorphic manifestations of the disease. ${ }^{9}$ In this study, it was observed that the incidence of single ring enhancing CT lesion is more prevalent in younger patients in the age group of $20-40$ years $(53.84 \%)$ and in the age group of $0-20$ years (38.46\%), with incidence more or less same in both genders. In a study of biopsy-proven lesion, Chandy and Rajshekhar ${ }^{10}$ reported that single enhancing CT lesion in the majority of patients represent dying cysticercus larva. Also, the disease Neurocysticercosis and Tuberculoma, the commonest diagnosis of these ring enhancing CT lesions were more prevalent in patients belonging to lower (63.46\%) socioeconomic status. This finding directly suggests the need of hygiene and health education by which the incidence can be brought down. Our study clearly suggests that in the majority of patients, these lesions disappear spontaneously after 8-12 weeks in $69.23 \%$ of cases.

\section{CONCLUSION}

Single ring enhancing CT lesion should also be considered in differential diagnosis of Indian patients presenting with nonepileptic neurological syndrome as they also have benign course. It is of prime importance to stress the earnest need of preventing aspect of the disease. Health education is of critical importance since humans are the exclusive definitive hosts of the parasite.

\section{REFERENCES}

[1] Chopra JS, Sawhney IM, Suresh N, et al. Vanishing CT lesions in epilepsy. J Neurol Sci 1992;107(1):40-9.

[2] Bhargava S, Tandon PN. CNS tuberculosis: lessons learnt from CT studies. Neurology India 1980;28:20712.

[3] Rajshekhar V. Etiology and management of single small CT lesions in patients with seizures: understanding a controversy. Acta Neurol Scand 1991;84(6):465-70.

[4] Garg RK, Nag D. Single ring or disk-enhancing computed tomographic lesion in Indian children and adolescents after first seizures. Arch Pediatr Adolesc Med 1997;151(6):632-4.

[5] Sethi PK, Kumar BR, Madan VS, et al. Appearing and disappearing CT scan abnormalities and seizures. J Neurol Neurosurg Psychiatry 1985;48(9):866-9.

[6] Padma MV, Behari M, Misra NK, et al. Albendazole in single CT ring lesions in epilepsy. Neurology 1994;44(7):1344-6.

[7] Rajshekhar V. Albendazole therapy of persistent, solitary cysticercus granulomas in patients with seizures. Neurology 1993;43(6):1238-40.

[8] Baranwal AK, Singhi PD, Khandelwal N, et al. Albendazole therapy in children with focal seizures and single small enhancing computerized tomographic lesions: a randomized, placebo-controlled, doubleblind trial. Pediatr Infect Dis J 1998;17(8):696-700.

[9] Murthy JM, Yangala R. Acute symptomatic seizuresincidence and aetiological spectrum: a hospital-based study from south India. Seizure 1999;8(3):162-5.

[10] Rajshekhar V, Haran RP, Prakash GS, et al. Differentiating solitary small cysticercus granuloma and tuberculomas in patients with epilepsy. Clinical and computerized tomographic criteria. J Neurosurg 1993;78(3):402-7. 